\title{
EFFECT OF A MALAY LANGUAGE PHONICS INTERVENTION ON THE DECODING SKILLS AND SELF-REGULATED LEARNING STRATEGIES OF OLDER PRIMARY SCHOOL STUDENTS WITH DYSLEXIA
}

\author{
Ann Sien Sut Lee and Lay Wah Lee*
}

School of Educational Studies, Universiti Sains Malaysia, Pulau Pinang, MALAYSIA

*Corresponding author: 1wah@usm.my

Published online: 30 April 2021

To cite this article: Ann Sien Sut Lee and Lay Wah Lee. 2021. Effect of a Malay language phonics intervention on the decoding skills and self-regulated learning strategies of older primary school students with dyslexia. Kajian Malaysia 39(1): 77-98. https://doi.org/10.21315/km2021.39.1.4

To link to this article: https://doi.org/10.21315/km2021.39.1.4

\begin{abstract}
A Malay language dyslexia intervention programme named "MyBaca" has been developed based on the Orton-Gillingham approach to teach Malay phonics knowledge and decoding skills to children with dyslexia. The present study investigated the effect of the phonics intervention in MyBaca on the decoding skills and self-regulated learning (SRL) strategies of older children with dyslexia. Three children aged 11 years with a dyslexia profile were sampled and taught the MyBaca phonics intervention in 36 individual sessions. An adapted single-subject research design was applied to gather decoding skills scores across baseline, treatment and maintenance phases. A participant observation method was used to gather qualitative narration on SRL strategies. The quantitative results indicate improvement in decoding skills after intervention, more significantly for phonics knowledge involving digraphs. The findings support that teaching of graphemephoneme knowledge, integrated with phonological manipulation skills within an explicit and systematic context is crucial for older children with dyslexia to acquire decoding skills. The qualitative results reveal the development of SRL facilitated by the tutor. In conclusion, the findings are significant as the broader implication is that the traditional syllable-spell method of teaching word reading is insufficient for children with dyslexia and they require more structured instruction in Malay
\end{abstract}


phonics as in the MyBaca programme. The Malay language teachers as well as the remedial and special education teachers need to be aware of these findings in order to ameliorate reading among children with dyslexia.

Keywords: dyslexia intervention, Malay language, decoding skills, self-regulated learning, MyBaca

\section{INTRODUCTION}

Dyslexia is identified with difficulties in accurate and/or fluent word recognition, poor spelling and decoding, and these difficulties result from a deficit in the phonological component of language that is often unexpected in relation to other cognitive abilities and the provision of effective classroom instruction (International Dyslexia Association 2002; Lyon, Shaywitz and Shaywitz 2003). Pedagogic principles of effective decoding skills intervention for children with dyslexia are well-established from both historical and empirical perspectives. Originating from the Orton-Gillingham approach (Henry 1998; Gillingham and Stillman 1956), supported by empirical evidence (e.g., National Reading Panel 2000), these principles are now framed within the Structured Literacy framework of the International Dyslexia Association (International Dyslexia Association 2019). A strong core of highly explicit, systematic teaching of foundational skills such as decoding and spelling is the basis for successful literacy interventions for children with reading disabilities.

According to Ehri (2005), children progress through four phases as they learn to decode words. These four phases are characterised by the type of alphabetic knowledge used namely pre-alphabetic, partial alphabetic, full alphabetic and consolidated alphabetic phases. Alphabetic knowledge, also referred to as grapheme-phoneme knowledge, is the knowledge of how graphemes typically symbolise phonemes in a word (Ehri 1998). It is knowledge of how letters (singleletter or multi-letter units) correspond to phonemes in a word. Ehri's phase theory is found to be relevant for the Malay language writing system (Lee, Low and Lee 2019). Children with dyslexia have difficulty decoding because of their problems acquiring full alphabetic knowledge. The full alphabetic knowledge of the Malay language writing system comprises of phonics knowledge of the 26 letters in the alphabet, five consonant digraphs $(g h, k h, n g, n y, s y)$ and three vowel digraphs (ai, au, oi) (Lee 2008; Lee, Low and Abdul Rashid 2013). As each of these graphemes matches onto a single phoneme, with the exception of grapheme $e$ which carries two vowel sounds, the Malay writing system is considered to be transparent. A transparent orthography allows children to follow graphemephoneme correspondence rules (Gupta and Jamal 2006). 
However, the traditional method of teaching Malay word reading does not take advantage of this transparent phonics knowledge. Instead, the spelling of letter names in correspondence to syllables is taught and this syllable-spell method is shown to induce reading errors among early low progress readers (Lee and Wheldall 2011).

A Malay language dyslexia intervention programme named MyBaca (Lee 2019) which takes advantage of this transparent phonics knowledge to help children acquire decoding skills has been developed. MyBaca is developed based on the Orton-Gillingham approach, which applies grapheme-phoneme knowledge, integrated with phonological manipulation skills within an explicit and systematic context. The MyBaca programme consists of multiple types of interventions. This article focuses on the phonics intervention aspect of MyBaca, which aims to teach alphabetic knowledge in order to acquire decoding skills. For this investigation, the alphabetic knowledge of Malay is sequenced into 14 knowledge units. A knowledge unit comprises a small set of alphabetic knowledge (e.g., knowledge Unit 1 teaches grapheme-phoneme knowledge of $a, k, b, i$ ) taught using a repertoire of phonics intervention strategies (refer to the methods section in this article for details). The first seven knowledge units (Level 1) deal with single-letter grapheme-phoneme knowledge (e.g., $a, k, b, i$ ), whereas the next seven knowledge units (Level 2) teaches multi-letter graphemephoneme knowledge (e.g., ng, sy). These knowledge units are sequenced cumulatively.

There is a need to provide evidence on the efficacy and effectiveness of an intervention programme in improving the reading skills of young struggling readers (Wheldall et al. 2017). Therefore, this study investigated the effect of the MyBaca phonics intervention on the decoding skills of children with dyslexia. Decoding is defined by Hoover and Tunmer (2018) as word recognition accomplished through alphabetic coding, which relates the letter sequences within a given word to the phonological structures underlying its pronunciation, thereby allowing access to the word's location in the mental lexicon.

In addition to decoding skills, this study also aimed to identify through observation, the self-regulated learning (SRL) processes that may be generated during the intervention sessions with the children. According to Zimmerman (2015), selfregulated learning refers to how students become masters of their own learning processes. Self-regulation is a self-directive process through which learners transform their mental abilities into task-related skills in areas of functioning, such as in reading. 
In a previous pilot study, we encountered a child's attempts at self-regulation to effect his own learning while being taught to decode (Lee, Yeap and Low 2012), which gave us the impetus to further describe systematically, events and behaviours on SRL in this investigation. The tutor's role in facilitating SRL is also investigated as according to the Orton-Gillingham approach, the tutor plays an important role in the intervention.

The three cyclical phase SRL model of Zimmerman (2000) is adopted as the theoretical model to guide qualitative analysis in this research. The Forethought phase refers to processes and belief that occur before efforts to learn, and there are two major classes of forethought phase processes: task analysis (goal setting and strategic planning) and self-motivation beliefs (self-efficacy, outcome expectations, intrinsic interest and learning goal orientation). The performance phase refers to processes that occur during behavioural intervention which fall into two major classes: self-control (imagery, self-instruction, attention focusing and task strategies) and self-observation (self-recording and self-experimentation). The self-reflection phase refers to processes that occur after each learning effort and the processes are classified into two which are: self-judgement (self-evaluation and causal attribution) and self-reaction (self-satisfaction/affect and adaptive/ defensive).

\section{METHODOLOGY}

A mixed methodology was applied to gather quantitative and qualitative data. Ethical approval was obtained from Jawatankuasa Etika Penyelidikan Manusia Universiti Sains Malaysia (USM/JEPeM/15020046) to conduct this research. Decoding skills data was gathered using an adapted single-subject research design (Richard, Taylor and Ramasamy 2014). In this adapted method, data collection was fixed three times during the baseline phase (phase prior to treatment). As for the treatment phase, progress to the next knowledge unit was set at $70 \%$ mastery criterion, which means that current knowledge units had to be relearned until a $70 \%$ level was achieved. Subsequently, the maintenance data was collected after the fourth knowledge unit was taught. The maintenance data for each knowledge unit was gathered twice to determine whether the participants retained the skills mastered. When the $70 \%$ criterion was not maintained, booster treatment sessions (Mazzotti et al. 2010) were conducted. In the booster sessions, treatment of that particular knowledge unit was repeated. 
In order to monitor the reliability of the administration of the intervention and the valid reporting of the results, all the sessions were video-recorded. Prior to intervention, the participants were prepared for the video recording to avoid the observation effect (Fraenkel and Wallen 2009).

As for the qualitative aspect of data collection, the participant observation method (Kawulich 2005) was used to observe and describe the SRL situation during the study. The participant observer was a trained MyBaca tutor who provided the treatment in this study. With eight years of experience in remedial instruction of children with learning difficulties, the participant observer has the necessary background to observe and narrate the participants' behaviour during treatment.

\section{Sampling}

Older primary school students who had already received regular and remedial instruction in schools and yet still showed severe reading disabilities were purposely sampled to test the effect of the MyBaca phonics intervention. The initial screening was conducted at two primary schools with the help of the students' Malay language subject teachers. Eight primary students (from Grades 4 to 6) not having any physical, sensory or emotional disability were sampled by the teachers. Two dyslexia checklists were then administered to these students (Ministry of Education 2011; Lee 2005). Next, a battery of reading and phonological assessment tests to identify for dyslexia in Malay was administered (Lee 2008; 2009; 2011). Furthermore, samples of the students' Malay language school work were analysed for indications of dyslexia. The resultant assessment profile of each student was then discussed with an expert in Malay language dyslexia diagnosis. Seven students exhibited a profile of dyslexia based on the International Dyslexia Association (2002) definition. However, only three parents agreed to proceed with the treatment phase of the study which was conducted after formal school hours. The assessment results for the three participants are presented in Table 1. A description of the three participants, pseudo-named Henry, Kelvin and May are presented as follows:

1. Henry (aged 11 years and 3 months) is a shy, polite and soft-spoken boy. Despite his good behaviour, he did poorly in his academic subjects. His results (refer to Table 1) from the screening assessments show that he was very poor in phonological processing, decoding, spelling as well as in other Malay language literacy tasks. He displayed $b, d$ and $p$ letter confusion in his written school works. 
2. May (aged 11 years and 1 month) is talkative, rather untidy and cheerful. Her teachers complain that she is lazy, she sleeps during class and she often forgets to do her homework or misplaces her work. Her assessment results (refer to Table 1) indicate poor phonological processing, spelling and decoding skills. Although she scored $48 \%$ for real word reading, her reading was dysfluent and accompanied by an unexpected rhythm. She believed that she could only read accurately with that rhythm. Her handwriting was messy. She scored poorly in the reading and listening comprehension tasks probably due to her laborious reading and the lack of Malay language vocabulary.

3. Kelvin (aged 11 years and 8 months) is a neat, thin and tall boy. He was an athlete at his school. His parents believed he could not learn (academically) and that he was lazy. In general, his results from the assessments showed weak Malay language literacy skills. However, he did quite well in two of the phonological processing tasks (elision and blending). This can be explained by his three years of experience in attending a learning centre for children with poor academic skills. The learning centre teaches grapheme-phoneme correspondence in the English language and possibly cross-language transfer had occurred in his case. However, despite the three years of intervention at the learning centre he had not improved much. He had major confusions with the shape and sound of the letters $b, p, d$ and $t$. He read with low fluency and had unclear pronunciations. He had poor spelling and underdeveloped decoding skills. His reading and listening comprehension were extremely weak.

Table 1: Assessment profile of the participants

\begin{tabular}{lrrrc}
\hline Test & Henry & May & Kelvin & Max (\%) \\
\hline Word reading (\%) & 14 & 48 & 44 & 100 \\
Non-word reading (\%) & 0 & 0 & 0 & 100 \\
Letter naming (\%) & 100 & 100 & 100 & 100 \\
Spelling (\%) & 25 & 20 & 15 & 100 \\
RAN(s) & 20 & 41 & 17 & - \\
Digit span (digit) & 6 & 7 & 6 & - \\
Elision (\%) & 38 & 68 & 88 & 100 \\
Blending (\%) & 38 & 25 & 75 & 100 \\
Segmenting (\%) & 25 & 20 & 15 & 100 \\
Listening comprehension (\%) & 38 & 38 & 0 & 100 \\
Reading comprehension (\%) & 15 & 23 & 8 & 100 \\
\hline
\end{tabular}




\section{Intervention/Treatment}

The intervention consisted of one-hour individual sessions with each participant and was conducted three times per week. As was described at the introduction section of this article, the alphabetic knowledge of Malay was sequenced into two levels. The first level taught phonics elements involving only single-letter graphemes. Altogether, there were seven Knowledge Units in Level 1. Level 2 consisted of phonics elements involving consonant digraphs and vowel digraphs. There were also seven Knowledge Units in Level 2, with each unit focusing on a particular digraph. Each treatment session began with the introduction of a new set of grapheme-phoneme correspondence knowledge using a multisensory strategy, followed by revision of cumulative grapheme-phoneme correspondence knowledge taught up to that point. Next, a word building strategy involving blending and segmentation tasks was applied as the decoding-skills intervention strategy (Lee 2019). Further practice and review used word-reading and wordspelling strategies such as the multisensory "finger spelling" technique from the Orton-Gillingham approach. Each knowledge unit ended with reading of the MyBaca decodable texts (Lee and Low 2014). Figure 1 summarises the phonics intervention strategies in each knowledge unit. Depending on the participants' ability, a knowledge unit may be broken down and completed in a few sessions. The three participants in this study managed to complete all knowledge units within 36 sessions.

\section{Instruments}

The decoding skill was measured using non-word reading probes as the use of non-words highlight grapheme-phoneme translation difficulties. Three 10-word probes were developed for each knowledge unit (Word Probe A, Word Probe B and Word Probe $\mathrm{C}$ ). These probes were validated by three qualified evaluators. Next, parallel-form reliability was obtained by preliminary testing of the word probes with five students who present similar demographic characteristic to the participants in this study, but without reading problems (Gay, Mills and Airasian 2006; Kim 2009). The overall percentage of similarity across the three 10 -word probes from the same knowledge unit ranged from $78 \%$ to $81 \%$, indicating high parallel-form reliability (Rodriguez 2007). The 10-word probes (sets A, B, or C) for each knowledge unit were randomly picked and administered at the baseline, treatment and maintenance phases to avoid memorisation by the participants. 


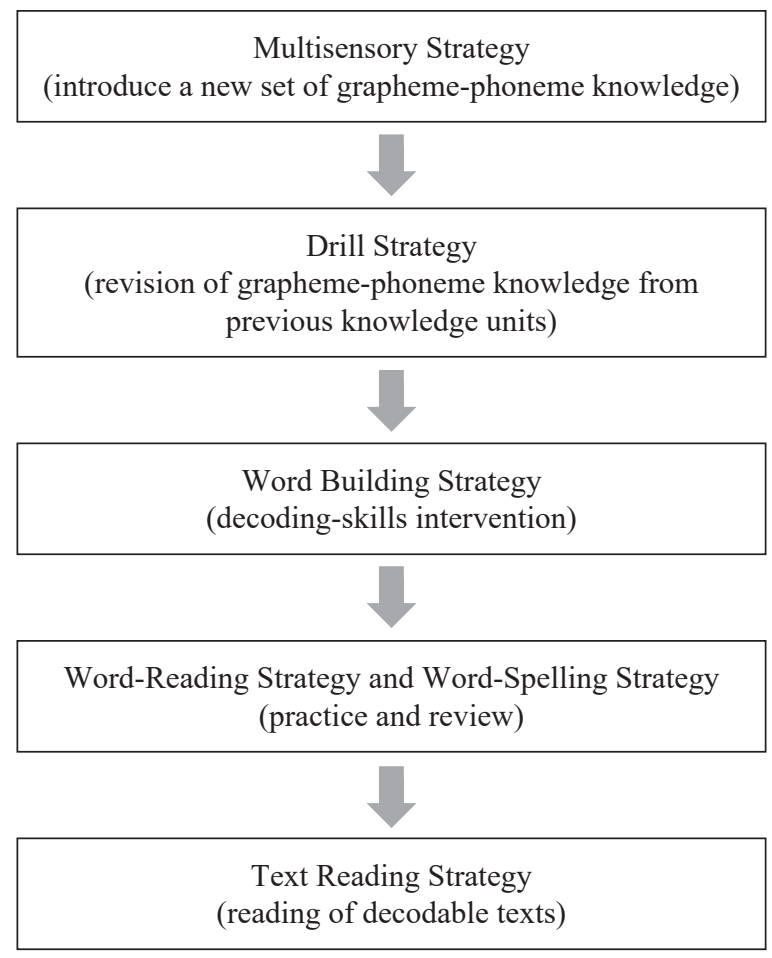

Figure 1: Phonics intervention strategies in each knowledge unit.

As for participant observation, field notes were the primary method of capturing the data. Notes taken to capture this data included records of what was observed, informal conversations with the participants, and the participant observer's reflections that were kept as journal writings after each session with the participants. The qualitative data was then analysed using the thematic analysis method (Braun and Clarke 2006).

\section{RESULTS}

\section{Treatment Fidelity}

To ensure treatment fidelity, the implementation of the intervention procedures was video-recorded and rated by the programme developer. Twenty-five percent of the videos were randomly picked and rated during the intervention phase. The result indicated that the phonics instruction in MyBaca was implemented with $99 \%$ accuracy across all the participants' treatment. 


\section{Decoding Skills}

The decoding skills scores for each participant across baseline, treatment and maintenance phases were computed into percentage scores and mean percentage scores. The percentage score is calculated based on the number of words read correct by the participant in the word-probe, divided by the total number of words in the word-probe (10 words), and computed to percentage. For example, if the participant read eight words correct, then the percentage score will be $(8 / 10) \times 100=80 \%$.

\section{Henry}

Henry's Level 1 word-probe scores across baseline, treatment and maintenance phases are summarised in Table 2. The individual baseline scores across all seven knowledge units ranged widely from $30 \%$ to $100 \%$, and the mean percentage scores of the seven knowledge units ranged from $36.7 \%$ to $73.3 \%$. These baseline scores indicate that prior to intervention, Henry was able to read some of the words in the probes using the traditional method. With treatment, the individual percentage scores increased to a higher range of $70 \%$ to $100 \%$ (mean percentage score range of $83.3 \%$ to $100 \%$ ). The results indicated that the decoding skills improved slightly across the baseline to treatment phase for Level 1 knowledge units.

However, a more significant improvement in the decoding skills was obtained for the Level 2 intervention (Table 3). During the baseline phase of Level 2, the individual scores across all the knowledge units were in the lower range of $0 \%$ to $50 \%$ (mean percentage scores ranged from $0 \%$ to $43.3 \%$ ). However, during the treatment phase, the individual decoding skills scores improved quite significantly to be in the high range of $70 \%$ to $100 \%$. The mean percentage scores of the seven knowledge units in Level 2 jumped from a baseline range of $0 \%$ to $43.3 \%$ to that of $83.3 \%$ to $100 \%$. This noteworthy improvement in decoding skills from baseline to treatment phases, which was maintained, can be safely attributed to the current intervention. 
Table 2: Summary of decoding skills scores for Henry across phases (Level 1)

\begin{tabular}{|c|c|c|c|c|c|c|c|c|}
\hline \multirow{2}{*}{ Phase } & \multirow{2}{*}{ Unit } & \multicolumn{7}{|c|}{ Level 1 (single-letter grapheme) } \\
\hline & & 1 & 2 & 3 & 4 & 5 & 6 & 7 \\
\hline \multirow[t]{2}{*}{ Baseline } & $\%$ score (range) & $40-70$ & $60-100$ & $50-80$ & $60-80$ & $20-60$ & $60-90$ & $30-50$ \\
\hline & Mean & 56.70 & 73.30 & 66.70 & 73.30 & 43.30 & 76.70 & 36.70 \\
\hline \multirow[t]{2}{*}{ Treatment } & $\%$ score (range) & $70-90$ & $90-100$ & $80-100$ & 100 & $70-100$ & $90-100$ & 100 \\
\hline & Mean & 83.30 & 96.70 & 93.30 & 100.00 & 83.30 & 93.30 & 100.00 \\
\hline \multirow[t]{2}{*}{ Maintenance } & $\%$ score (range) & $20-100$ & $60-90$ & $90-100$ & $90-100$ & 100 & $90-100$ & 100 \\
\hline & Mean & 68.33 & 80.00 & 96.67 & 96.67 & 100.00 & 96.67 & 100.00 \\
\hline
\end{tabular}

Table 3: Summary of decoding skills scores for Henry across phases (Level 2)

\begin{tabular}{llccccccc}
\hline \multirow{2}{*}{ Phase } & Unit & \multicolumn{7}{c}{ Level 2 (digraphs and diphthongs) } \\
\cline { 2 - 9 } & & 1 & 2 & 3 & 4 & 5 & 6 & 7 \\
\hline Baseline & \% score (range) & $0-10$ & $10-30$ & 0 & $30-40$ & $0-10$ & $30-50$ & $30-50$ \\
& Mean & 6.70 & 16.70 & 0.00 & 36.70 & 3.30 & 43.30 & 43.30 \\
\multirow{3}{*}{ Treatment } & \% score (range) & 100 & $80-100$ & $90-100$ & $70-100$ & $90-100$ & 100 & $70-100$ \\
& Mean & 100.00 & 90.00 & 93.30 & 86.70 & 93.30 & 100.00 & 83.30 \\
Maintenance & \% score (range) & $80-100$ & 90 & 80 & 100 & 100 & $90-100$ & 100 \\
& Mean & 90.00 & 90.00 & 80.00 & 100.00 & 100.00 & 95.00 & 100.00 \\
\hline
\end{tabular}

\section{May}

Referring to Table 4, May was able to read most of the words in the Level 1 word-probes prior to intervention using the traditional method taught in school. The baseline individual scores were within a range of $50 \%$ to $100 \%$, with a mean percentage score range of $60 \%$ to $100 \%$. With intervention, the scores did improve slightly to reach ceiling levels of $80 \%$ to $100 \%$ (mean percentage score range of $86.7 \%$ to $96.7 \%$ ). Improvement was more drastic at Level 2 (refer to Table 5). Prior to Level 2 intervention, May's individual baseline scores across all Level 2 knowledge units range from $0 \%$ to $80 \%$, with mean percentage score range of $10 \%$ to $66.7 \%$. With treatment, her individual scores improved to a higher range of $60 \%$ to $100 \%$ (mean percentage score range of $72.5 \%$ to 96.7\%). The improvement after intervention for May was more drastic at Level 2. This improvement was maintained. 
Table 4: Summary of decoding skills scores for May across phases (Level 1)

\begin{tabular}{llccccccc}
\hline \multirow{2}{*}{ Phase } & Unit & \multicolumn{7}{c}{ Level 1 (single-letter grapheme) } \\
\cline { 2 - 8 } & & 1 & 2 & 3 & 4 & 5 & 6 & 7 \\
\hline Baseline & \% score (range) & $70-80$ & 100 & $70-100$ & $80-100$ & $80-100$ & $80-90$ & $50-70$ \\
& Mean & 76.70 & 100.00 & 83.30 & 86.70 & 86.70 & 86.70 & 60.00 \\
\multirow{2}{*}{ Treatment } & \% score (range) & $80-100$ & $90-100$ & $90-100$ & $90-100$ & $80-90$ & $90-100$ & $80-90$ \\
& Mean & 93.30 & 96.70 & 96.70 & 93.30 & 86.70 & 93.30 & 86.70 \\
Maintenance & \% score (range) & $90-100$ & 100 & $90-100$ & $80-100$ & 100 & 100 & 90 \\
& Mean & 95.00 & 100.00 & 96.67 & 93.33 & 100.00 & 100.00 & 90.00 \\
\hline
\end{tabular}

Table 5: Summary of decoding skills scores for May across phases (Level 2)

\begin{tabular}{llccccccc}
\hline \multirow{2}{*}{ Phase } & Unit & \multicolumn{7}{c}{ Level 2 (digraphs and diphthongs) } \\
\cline { 2 - 8 } & & 1 & 2 & 3 & 4 & 5 & 6 & 7 \\
\hline Baseline & \% score (range) & 10 & $10-20$ & 0 & $0-30$ & $30-70$ & $40-80$ & $30-50$ \\
& Mean & 10.00 & 13.30 & 0.00 & 16.70 & 56.70 & 66.70 & 44.30 \\
Treatment & \% score (range) & $70-90$ & $60-90$ & $90-100$ & $80-100$ & $90-100$ & $90-100$ & $80-100$ \\
& Mean & 76.70 & 72.50 & 96.70 & 93.30 & 93.30 & 96.70 & 94.30 \\
Maintenance & \% score (range) & $70-90$ & $70-90$ & $90-100$ & $90-100$ & 100 & 100 & 100 \\
& Mean & 80.00 & 80.00 & 95.00 & 95.00 & 100.00 & 100.00 & 100.00 \\
\hline
\end{tabular}

\section{Kelvin}

Kelvin's Level 1 scores are presented in Table 6. Kelvin's baseline individual scores were in the range of $20 \%$ to $100 \%$ (mean percentage score range, $46.7 \%$ to $96.7 \%$ ), and these scores improved with treatment to a range of $50 \%$ to $100 \%$ (mean percentage score range of $73.3 \%$ to $96.7 \%$ ). As with the other two participants, intervention results were more significant for Level 2 (Table 7). The individual scores increased from a range of $0 \%$ to $100 \%$ (mean percentage score range of $3.3 \%$ to $93.3 \%$ ) to that of $70 \%$ to $100 \%$ (mean percentage score range of $83.3 \%$ to $96.7 \%$ ). The results indicated a slight increase from baseline to treatment phases for Level 1 and more significant increase in scores from baseline to treatment phases for Level 2. The improvement in scores during treatment was maintained. 
Table 6: Summary of decoding skills scores for Kelvin across phases (Level 1)

\begin{tabular}{llccccccc}
\hline \multirow{2}{*}{ Phase } & Unit & \multicolumn{7}{c}{ Level 1 (single-letter grapheme) } \\
\cline { 2 - 8 } & & 1 & 2 & 3 & 4 & 5 & 6 & 7 \\
\hline \multirow{2}{*}{ Baseline } & \% score (range) & $20-80$ & $90-100$ & $70-80$ & 70 & $60-80$ & $60-100$ & 70 \\
& Mean & 46.70 & 96.70 & 76.70 & 70.00 & 66.70 & 83.30 & 70.00 \\
\multirow{3}{*}{ Treatment } & \% score (range) & $50-90$ & 100 & $80-100$ & $90-100$ & $90-100$ & $90-100$ & $90-100$ \\
& Mean & 73.30 & 100.00 & 90.00 & 96.70 & 93.30 & 96.70 & 96.70 \\
Maintenance & \% score (range) & 100 & 100 & 100 & 100 & 100 & 100 & $90-100$ \\
& Mean & 100.00 & 100.00 & 100.00 & 100.00 & 100.00 & 100.00 & 95.00 \\
\hline
\end{tabular}

Table 7: Summary of decoding skills score for Kelvin across phases (Level 2)

\begin{tabular}{llccccccc}
\hline \multirow{2}{*}{ Phase } & Unit & \multicolumn{7}{c}{ Level 2 (digraphs and diphthongs) } \\
\cline { 2 - 8 } & & 1 & 2 & 3 & 4 & 5 & 6 & 7 \\
\hline \multirow{2}{*}{ Baseline } & \% score (range) & $0-10$ & $0-30$ & $0-20$ & $0-10$ & $90-100$ & 90 & $10-50$ \\
& Mean & 6.70 & 13.30 & 6.70 & 3.30 & 93.30 & 90.00 & 33.30 \\
\multirow{3}{*}{ Treatment } & \% score (range) & $80-90$ & $80-100$ & $70-100$ & $90-100$ & $90-100$ & $90-100$ & $80-100$ \\
& Mean & 83.30 & 90.00 & 86.70 & 93.30 & 96.70 & 93.30 & 94.30 \\
\multirow{3}{*}{ Maintenance } & \% score (range) & $80-100$ & $50-80$ & 100 & 100 & 100 & 90 & $80-100$ \\
& Mean & 90.00 & 70.00 & 100.00 & 100.00 & 100.00 & 90.00 & 91.67 \\
\hline
\end{tabular}

\section{SRL Narrative}

The qualitative data collected in the field notes during the participant observation were analysed using the thematic analysis method (Braun and Clarke 2006). Subthemes related to the SRL were arranged in a table according to Zimmerman's Self Regulation Phases (Zimmerman 2000) for each participant.

\section{Henry}

Regarding Henry's forethought phase process, during the first three baseline phases (no treatment involved), Henry read the words softly. However, he read with more confidence as the intervention progressed. He was motivated to learn during Level 1 but became more enthusiastic at Level 2. He also learned to selfcheck his scores. During the performance phase, he began by using the method taught in the school (traditional method) to read even though he did not have mastery over it. Although he was focused and task-oriented, he failed to read. 
He gradually acquired the new grapheme-phoneme phonics approach to decode words and became aware of the errors he made. In Level 2, he was able to try different ways to read the new words during baseline testing. In his self-reflection phase, he began to adapt and apply decoding skills taught in the intervention. At Level 2, he attributed his improvement to the new grapheme-phoneme phonics approach and was able to evaluate his own performance. Table 8 presents the sub-themes from Henry's attempts at SRL.

Table 8: Sub-themes of Henry's SRL

\begin{tabular}{|c|c|}
\hline Level 1 & Level 2 \\
\hline Forethought & Forethought \\
\hline 1. Not confidence/read softly & 1. Eager to begin \\
\hline \multirow{2}{*}{$\begin{array}{l}\text { 2. Look interested with bingo game, } \\
\text { excited with bingo game }\end{array}$} & 2. Eager to try \\
\hline & 3. Confident \\
\hline 3. Confidence improved & 4. Kept trying \\
\hline \multirow[t]{4}{*}{ 4. Motivated to try } & 5. Determined to complete the task \\
\hline & 6. Excited to guess the new phonemes \\
\hline & 7. Tried hard to recall \\
\hline & 8. Checked his scores \\
\hline Performance & Performance \\
\hline $\begin{array}{l}\text { 1. Whispered the school method while } \\
\text { applying it }\end{array}$ & $\begin{array}{l}\text { 1. Focused, concentrated to solve } \\
\text { problem }\end{array}$ \\
\hline 2. Finger pointing & 2. Guessing new phonemes \\
\hline 3. Used school method but failed & 3. Paused \\
\hline 4. Guessed new phonemes & 4. Read slowly \\
\hline 5. Focused, concentrated & \multirow{2}{*}{$\begin{array}{l}\text { 5. Used a mixture of new and old } \\
\text { method }\end{array}$} \\
\hline 6. Not aware of letter $b / d$ errors & \\
\hline 7. Read carefully, slowly & 6. Aware of mistakes made \\
\hline 8. Blended slowly & \multirow{2}{*}{$\begin{array}{l}\text { 7. Told tutor he cannot identify the } \\
\text { second syllable/asked for help }\end{array}$} \\
\hline 9. Paused & \\
\hline $\begin{array}{l}\text { 10. Aware he cannot read without } \\
\text { grapheme-phoneme knowledge }\end{array}$ & $\begin{array}{l}\text { 8. Tried different ways to guess new } \\
\text { phonemes }\end{array}$ \\
\hline 11. Became aware of $b / d$ errors & 9. Extracted new grapheme-phoneme \\
\hline 12. Whispered the new phonics method & \multirow{2}{*}{$\begin{array}{l}\text { knowledge from familiar words } \\
\text { 10. Was not aware of familiar word error }\end{array}$} \\
\hline $\begin{array}{l}\text { 13. Switched from traditional method to } \\
\text { phonics approach }\end{array}$ & \\
\hline
\end{tabular}

(Continued on next page) 
Table 8 (continued)

\begin{tabular}{|c|c|}
\hline Level 1 & Level 2 \\
\hline Self-reflection & Self-reflection \\
\hline $\begin{array}{l}\text { 1. Applied "finger spell" technique } \\
\text { (multisensory) }\end{array}$ & $\begin{array}{l}\text { 1. Performed silent multisensory syllable } \\
\text { segmentation technique to recall }\end{array}$ \\
\hline 2. Performed silent "finger spell' technique & 2. Self-correction \\
\hline 3. Self-correction & 3. Performed silent "finger spell" technique \\
\hline 4. Asked the tutor to repeat & 4. Used "finger spell" technique without \\
\hline 5. Watched tutor's lip movement & action \\
\hline 6. Developed winning strategy for bingo & 5. Repeated word to recall/remember \\
\hline 7. Applied multisensory reading technique & 6. Satisfied with improvement \\
\hline 8. Used new blending method & 7. Attribute the improvement to the new \\
\hline $\begin{array}{l}\text { 9. Applied "thumb reading" technique } \\
\text { (multisensory) }\end{array}$ & $\begin{array}{l}\text { phonics approach } \\
\text { 8. Aware that his Malay reading skills have }\end{array}$ \\
\hline 10. Self-practice before testing session & \\
\hline 11. Satisfied with own improvement & 9. Used multisensory reading technique \\
\hline 12. Repeated many times when not sure & 10. Applied "thumb reading" technique \\
\hline 13. Checked his scores & 11. Applied new blending method \\
\hline & 12. Used own modified procedure to blend \\
\hline & 13. Performed "finger spell technique" \\
\hline & 14. Self-evaluated sessions \\
\hline & 15. Developed a sequence to read words \\
\hline & $\begin{array}{l}\text { 16. Applied "cover syllable" technique } \\
\text { (multisensory) }\end{array}$ \\
\hline
\end{tabular}

May

In Level 1, May's forethought phase process showed she was confident to read using the method taught in school (traditional method). Initially she believed that she needed to read with a certain rhythm. However, she dropped this behaviour as the intervention progressed. She was troubled by her low baseline scores at Level 2 but became more confident as she developed the decoding skills which she did not master fully during Level 1. Regarding her performance phase, like Henry she had developed her own strategies to support learning (e.g., fingerpointing method to differentiate $b$ from $d$ ). May applied more new strategies to support intervention at Level 2. During her self-reflection phase, May was able to evaluate tasks, did self-correction and applied the new decoding skills method. In Level 2, she adapted more skills from the intervention which proved to be effective for her. Table 9 presents the sub-themes of May's SRL. 
Table 9: Sub-themes of May's SRL

\begin{tabular}{|c|c|}
\hline Level 1 & Level 2 \\
\hline Forethought & Forethought \\
\hline 1. Belief she can only read with rhythm & 1. Rejected break offer \\
\hline 2. Liked bingo game & 2. Read with confidence \\
\hline 3. Determined to complete task & 3. Wanted to do without assistance \\
\hline 4. Initiative in learning & 4. Excited to do it by herself \\
\hline 5. Read with confidence & 5. Challenged herself \\
\hline 6. Aimed for $100 \%$ & 6. Determined to complete task \\
\hline 7. Rejected break offer & 7. Thought the non-words sounded funny \\
\hline Performance & Performance \\
\hline 1. Finger pointing & 1. Used blending to guess new phonemes \\
\hline 2. Asked for the meaning of word & 2. Aware of many errors made \\
\hline 3. Read in rhythm & 3. Used old and new blending methods \\
\hline 4. Used school traditional method & 4. Guessed new phonemes \\
\hline 5. Used own method to differentiate & 5. Self-practice many times \\
\hline$b$ and $d$ (b-boy, $d$-donkey) & 6. Aware that practice produce better result \\
\hline 6. Guessed new phonemes & 7. Asked tutor to repeat \\
\hline 7. Slowed down reading speed & 8. Asked for more time to guess and to do \\
\hline 8. Asked for answer & task \\
\hline 9. Focused & 9. Used analogy \\
\hline 10. Tried hard to blend & 10. Read slowly, with pause, carefully \\
\hline 11. Aware of error & 11. Finger pointing \\
\hline \multirow[t]{3}{*}{ 12. Counted total task to complete } & 12. Used shape of mouth to remember $/ u /$ \\
\hline & $\begin{array}{l}\text { 13. Extracted new grapheme-phoneme } \\
\text { correspondences from a familiar word }\end{array}$ \\
\hline & 14. Asked for meaning of some words \\
\hline Self-reflection & Self-reflection \\
\hline 1. Tried new blending method & 1. Applied "finger spell" technique to recall \\
\hline \multirow{2}{*}{$\begin{array}{l}\text { 2. Satisfied with her improvement at } \\
\text { school }\end{array}$} & 2. Discussed $b / d$ error with tutor \\
\hline & 3. Applied "thumb reading" technique \\
\hline 3. Evaluated tasks & 4. Applied "cover syllable" technique \\
\hline 4. Applied "thumb reading" technique & \multirow{2}{*}{$\begin{array}{l}\text { 5. Evaluated "finger spell" technique/aware } \\
\text { it helps }\end{array}$} \\
\hline 5. Used "cover syllable" technique & \\
\hline 6. Self-correction & 6. Closed eyes to write so to remember \\
\hline \multirow[t]{3}{*}{ 7. Checked scores } & 7. Self-correction \\
\hline & 8. Satisfied with her learning progress \\
\hline & 9. Checked scores \\
\hline
\end{tabular}




\section{Kelvin}

During the forethought phase, Kelvin learned to check and compare his scores between baseline and treatment phases. He was eager to learn and was confident to get the new grapheme-phoneme knowledge right at Level 2. In the performance phase, Kelvin used more skills in Level 2 than in Level 1. He was more aware of specific mistakes (e.g., $b$ and $p$ confusion). Regarding his self-reflection phase, he initiated a few discussions with the tutor about his learning purpose and strategy. He adapted more decoding skills as he progressed. Table 10 presents the subthemes from Kelvin's SRL development.

Table 10: Sub-themes for Kelvin's SRL

\begin{tabular}{|c|c|}
\hline Level 1 & Level 2 \\
\hline Forethought & Forethought \\
\hline 1. On-time & 1. Tried \\
\hline 2. Eager to learn, excited to learn & 2. Not confident \\
\hline \multirow[t]{4}{*}{ 3. Read with confidence } & $\begin{array}{l}\text { 3. Eager to know the new grapheme- } \\
\text { phoneme knowledge }\end{array}$ \\
\hline & $\begin{array}{l}\text { 4. Belief he can guess the phonemes } \\
\text { correctly }\end{array}$ \\
\hline & 5. Motivated to try \\
\hline & 6. Read with confidence \\
\hline Performance & Performance \\
\hline 1. Rocked back and forth to concentrate & 1. Guessed the new phonemes \\
\hline 2. Self-practice silently the $/ b /$ & 2. Read with pause, and care \\
\hline 3. Used the school method & 3. Aware of mistake \\
\hline \multirow[t]{5}{*}{ 4. Used new blending method } & 4. Used air-writing technique \\
\hline & 5. Used analogy \\
\hline & 6. Aware/sensitive to the letter's position \\
\hline & $\begin{array}{l}\text { 7. Extracted new grapheme-phoneme } \\
\text { knowledge from familiar word }\end{array}$ \\
\hline & 8. Asked to be retested \\
\hline
\end{tabular}

(Continued on next page) 
Table 10 (continued)

\begin{tabular}{|c|c|}
\hline Level 1 & Level 2 \\
\hline Self-reflection & Self-reflection \\
\hline 1. Self-correction & 1. Adapted word building strategy \\
\hline 2. Aware of error $/ b /$ & 2. Self-correction \\
\hline 3. Applied "finger spell" technique & 3. Asked tutor to repeat \\
\hline 4. Used school method & 4. Applied "cover syllable" technique \\
\hline 5. Used new blending method & 5. Discussed with tutor ways to improve his \\
\hline 6. Applied "thumb reading" technique & Malay language \\
\hline 7. Satisfied with his reading speed & 6. Evaluated the programme/not helping in \\
\hline 8. Asked tutor to repeat & achievement at school \\
\hline 9. Read slowly, carefully, with pause & 7. Asked for tips to guess the new phonemes \\
\hline 10. Developed winning strategy for bingo & 8. Evaluated own sessions \\
\hline 11. Checked scores & 9. Asked for more time \\
\hline & 10. Used new blending method to blend \\
\hline & 11. Discussed with tutor the fear of failure \\
\hline & 12. Dissatisfied with the result \\
\hline
\end{tabular}

Overall, Tables 8, 9 and 10 show that as the intervention progressed, there were significant developments of SRL strategies throughout from Level 1 to Level 2. It was noticed that the participants gradually developed more SRL strategies. They read with more confidence and were able to set goals and self-monitor their learning as the intervention progressed. The participants showed persistence when confronted with difficult tasks and even challenged themselves with more difficult tasks such as asking the tutor to let them build the new word without tutor direction. Their increased confidence had led to the reduction of their fear complex when confronted with difficulty in learning. The tutor noted that the participants' own dedication impacted their achievement. When they scored very poorly during the baseline phase at Level 2, they looked sad and disappointed, and the tutor had to remind them that these were baseline tests, which they had yet to learn the content, and showed them the proofs of improvement from the previous baseline and treatment phase scores. The MyBaca baseline and treatment assessments provided the recording proof for their progress. They experienced success and were able to monitor their own progress through these scores. Such successful experiences was rarely experienced in school. Letter confusion was not totally eliminated. However, the participants were more sensitive and aware of the confusion after the remediation, and they were able to self-correct the errors. They would slow down their reading speed for words containing letters $b, p$ and $d$. 


\section{Tutor's Role}

The tutor's role appeared to affect the development of SRL strategies among the participants. For example, during the intervention period, the participants experienced difficulties getting the correct sound of a certain phoneme or syllable. The tutor aided by matching the phoneme to a similar sounding word in Mandarin, for example $/ u$ / with a mandarin word (屋/house). The use of analogical reasoning, whereby the new information is connected with the prior knowledge by means of visual or acoustic cue helped them to better grasp the correct sound (Mastropieri, Sweda and Scruggs 2000). This analogical reasoning was used by May; she gave meaning to the sound /ny/ which she analogised to a cat's meow and the sound of / au/ was associated to a scream of pain (ouch). She was using auditory and semantic association to remember the sounds, a strategy she used to help her learn.

The tutor guided the participants to self-monitor and evaluate their own scores and helped them to set achievable goals for success. This guidance helped the participants to be more aware of their own progress. Furthermore, the discussion about knowledge concepts (e.g., phonemes to word, digraphs, etc.) gave them a better understanding of their own ability and encouraged them to be more responsible for their own learning and to better plan their learning strategy. The discussion on the errors made helped them to be more aware of their mistakes.

\section{DISCUSSION}

\section{Effect on Decoding Skills}

The quantitative results indicate that prior to the MyBaca phonics intervention, the traditional syllable-spell reading method taught in school enabled the older children with dyslexia to read some real words correctly, especially words that involve only single-letter graphemes. However, this traditional method was insufficient for them to decode words involving more advanced phonics elements such as digraphs. The results of this investigation show that the MyBaca phonics intervention which integrates grapheme-phoneme correspondence knowledge together with phonological blending and segmenting skills is necessary for accurate decoding of Malay words. It appears that the traditional method does not provide sufficient knowledge and skills for the children with dyslexia to acquire full alphabetic knowledge. In general, the findings support well-established pedagogic principles of teaching children with dyslexia (Gillingham and Stillman 1956; International Dyslexia Association 2019; National Reading Panel 2000) 
from the perspective of another writing system. Despite the transparency of the Malay writing system, children with dyslexia still require a systematic and explicit pedagogy of structured literacy (International Dyslexia Association 2019; National Reading Panel 2000) and Orton-Gillingham based multisensory strategies (Gillingham and Stillman 1956) which are integrated into the MyBaca phonics intervention (Lee 2019) in order to acquire full alphabetic knowledge. The intensive, systematic and explicit phonics instruction in MyBaca close the gap for the older children with dyslexia who were languishing in the partial alphabetic knowledge phase of word development despite regular and remedial instructions in school. The MyBaca phonics intervention propelled them to the next phase of word development, which is the full alphabetic knowledge phase. This conclusion can be safely made as a similar pattern of decoding skills improvement was replicated across all the three students after intervention using the intensive MyBaca phonics intervention.

\section{Effect on SRL}

The qualitative results revealed two main elements that contribute to the SRL development during the intervention. First, the design of the MyBaca phonics intervention is structured into small knowledge units to provide achievable goals and to encourage self-monitoring. Second, the tutor's involvement quite rightly facilitated the participants' SRL process. These two elements work together to promote SRL in the participants. The findings also support the notion of individual differences among children with dyslexia (Snowling and Griffiths 2004) as they develop their own SRL strategies to overcome their difficulties in learning.

These students have experienced countless failures in their Malay language subject throughout their five years in primary school, which had resulted in their low confidence and fear of failure in learning the subject. In the beginning of the intervention, they read with low confidence (e.g., softly, with uncertainty), and one of them even discussed his fear of failure with the tutor. They had been attributing their success to mere luck and failure to their own ability. Through selfmonitoring of their scores from baseline to intervention phases, they experienced success. As the intervention progressed, their confidence grew. As suggested by Zimmerman (2002) based on SRL, previous successful experiences not only motivated students to engage in the use of the method, but also enabled them to modify the technique to suit the situation. They also shared how they were now applying the skills at school. Kelvin developed an elimination strategy to build words and a winning strategy for the bingo games. Henry adapted the "finger spell" technique by performing it silently in school. 
The study revealed the tutor's role in the development of SRL strategies among the participants. The implication from this is that beginner tutors that use MyBaca will benefit from guided training by experienced tutors. The element of guided training would improve the intervention design for future implementation.

\section{CONCLUSION}

The present study investigated the effect of the MyBaca phonics intervention on decoding skills and SRL strategies. The findings from the study show that teaching of grapheme-phoneme knowledge, integrated with phonological manipulation skills within an explicit and systematic context is crucial for older children with dyslexia to acquire full alphabetic knowledge in Malay word recognition. Overall, the findings are significant as the broader implication of the findings is that the traditional syllable-spell method of teaching word reading is insufficient for children with dyslexia. The children with dyslexia require more structured instruction in Malay phonics as in the MyBaca programme (Lee 2019). It is hoped that such evidence-based research will prompt Malay language teachers, remedial and special education teachers to explore beyond the current traditional syllablespell method of teaching word reading as even though the current method is adequate for typically developing children, it is clearly insufficient to ameliorate reading among children with dyslexia.

\section{ACKNOWLEDGEMENTS}

This work was supported by the Universiti Sains Malaysia grant (Grant no. 304/ PGURU/6312002).

\section{REFERENCES}

Braun, V. and V. Clarke. 2006. Using thematic analysis in psychology. Qualitative Research in Psychology 3(2):77-101. https://doi.org/10.1191/1478088706qp063oa

Ehri, L.C. 1998. Grapheme-phoneme knowledge is essential to learning to read words in English. In Word recognition in beginning literacy, eds. J.L. Metsala and L.C. Ehri, 3-40. New York: Lawrence Erlbaum Associates Publishers. 2005. Learning to read words: Theory, findings and issues. Scientific Studies of Reading 9:167-188.

Fraenkel, J.R. and N.E. Wallen. 2009. How to design and evaluate research in education. Boston: McGraw-Hill. 
Gay, L., G. Mills and P. Airasian. 2006. Educational research: Competencies for analysis and application. 8th ed. New York: Prentice Hall.

Gillingham, A. and B.W. Stillman. 1956. Remedial training for children with specific disability in reading spelling and penmanship. 5th ed. Bronxville, NY: Author.

Gupta, A. and G. Jamal. 2006. An analysis of reading errors of dyslexic readers in Hindi and English. Asia Pacific Disability Rehabilitation Journal 17(1): 73-86.

Henry, M.K. 1998. Structured, sequential, multisensory teaching: The Orton legacy. Annals of Dyslexia 68: 3-26. https://doi.org/10.1007/s11881-998-0002-9

Hoover, W.A. and W.E. Tunmer. 2018. The simple view of reading: Three assessments of its adequacy. Remedial and Special Education 39(5): 304-312. https://doi .org/10.1177/0741932518773154

International Dyslexia Association. 2002. Definition of dyslexia. https://dyslexiaida.org/ definition-of-dyslexia/ (accessed 10 March 2021).

2019. Structured literacy works, but what is it? https://dyslexiaida.org/ structuredliteracy/ (accessed 2 Nov 2019).

Kawulich, B. 2005. Participant observation as a data collection method. Forum Qualitative Sozialforschung/Forum: Qualitative Social Research 6(2): art. 43. https://doi.org/10.17169/fqs-6.2.466

Kim, Y.M. 2009. Validation of psychometric research instruments: The case of information science. Journal of the America Society for Information Science and Technology 60(6): 1178-1191. https://doi.org/10.1002/asi.21066

Lee, L.W. 2005. Senarai semak disleksia. Pulau Pinang: School of Educational Studies, Universiti Sains Malaysia.

2008. Development and validation of a reading-related assessment battery in Malay for the purpose of dyslexia assessment. Annals of Dyslexia 58: 37-57. https://doi.org/10.1007/s11881-007-0011-0

2009. Ujian bacaan untuk mengenalpasti disleksia. Pulau Pinang: Basic Education Research Unit, Universiti Sains Malaysia.

2011. Ujian pemprosesan fonologi untuk mengenalpasti disleksia. Pulau Pinang:

Basic Education Research Unit, Universiti Sains Malaysia.

2019. Design and development of a Malay word recognition intervention program for children with dyslexia. Australian Journal of Learning Difficulties 24(2): 163-179. https://doi.org/10.1080/19404158.2019.1661261

Lee, L.W., H.M. Low and Abdul Rashid Mohamed. 2013. A comparative analysis of word structures in Malay and English children's stories. Pertanika Journal of Social Sciences \& Humanities 21(1): 67-84.

Lee, L.W. and H.M. Low. 2014. The development and application of an online Malay language corpus-based lexical database. Kajian Malaysia 32(Supp.1): 151-166.

Lee, L.W., H.M. Low and S.S. Lee. 2019. Exploring phoneme-grapheme connections in Malay word building. Writing Systems Research 11(1): 12-25. https://doi.org/10 $.1080 / 17586801.2019 .1662533$

Lee, L.W. and K. Wheldall. 2011. Acquisition of Malay word recognition skills: Lessons from low-progress early readers. Dyslexia 17(1): 19-37. https://doi.org/10.1002/ dys. 421 
Lee, L.W., M.C. Yeap and H.M. Low. 2012. Lessons learned from piloting a treatment decoding programme with a young Malay student with dyslexia. The Asia-Pacific Education Researcher 21(2): 286-295.

Lyon, G.R., S.E. Shaywitz and B.A. Shaywitz. 2003. Defining dyslexia, comorbidity, teachers' knowledge of language and reading: A definition of dyslexia. Annals of Dyslexia 53: 1-14. https://doi.org/10.1007/s11881-003-0001-9

Mastropieri, M.A., J. Sweda and T.E. Scruggs. 2000. Putting mnemonic strategies to work in an inclusive classroom. Learning Disabilities Research \& Practice 15: 69-74. https://doi.org/10.1207/SLDRP1502_2

Mazzotti, V.L., D.W. Test, C.L. Wood and S. Richter. 2010. Effects of computerassisted instruction on students' knowledge of postschool options. Career Development for Exceptional Individuals 33(1): 25-40. https://doi.org/10.1177/ 0885728809338714

Ministry of Education. 2011. Dyslexia checklist. Putrajaya: Special Education Department, Malaysia Ministry of Education.

National Reading Panel. 2000. Teaching children to read: An evidence-based assessment of scientific research literature on reading and its implications for reading instruction. National Institute of Child Health and Human Development. https://www.nichd.nih.gov/sites/default/files/publications/pubs/nrp/Documents/ report.pdf (accessed 10 March 2021).

Richard, S.B., R.L. Taylor and R. Ramasamy. 2014. Single subject research: Application in educational and clinical settings. 2nd ed. Belmont, CA: Wadsworth, Cengage Learning.

Rodriguez, M.C. 2007. Parallel forms reliability. In Encyclopedia of measurement and statistics, ed. N.J. Salkind, 731. Thousand Oaks, CA: Sage.

Snowling, M.J. and Y.M. Griffiths. 2004. Individual differences in dyslexia. In Handbook of children's literacy, 383-402. London: Kluwer Press. https://doi .org/10.1007/978-94-017-1731-1_21

Wheldall, K., R. Wheldall, A. Madelaine, M. Reynolds and S. Arakelian. 2017. Further evidence for the efficacy of an evidence-based, small group, literacy intervention program for young struggling readers. Australian Journal of Learning Difficulties 22(1): 3-13. https://doi.org/10.1080/19404158.2017 .1287102

Zimmerman, B.J. 2000. Attaining self-regulation: A social cognitive perspective. In Handbook of self-regulation, eds. M. Boekaerts, P.R. Pintrich, and M. Zeidner, 13-40. San Diego, CA: Academic Press. https://doi.org/10.1016/B978 $-012109890-2 / 50031-7$

2002. Becoming a self-regulated learner: an overview. Theory Into Practice 41(2): 64-70. https://doi.org/10.1207/s15430421tip4102_2

2015. Self-regulated learning: Theories, measures, and outcomes. In International encyclopedia of the social \& behavioral sciences, 2nd ed., ed. J.D. Wright, 541-546. https://doi.org/10.1016/B978-0-08-097086-8.26060-1. 